\title{
A Dynamic Analysis of the Role of the Planetary- and Synoptic-Scale in the Summer of 2010 Blocking Episodes over the European Part of Russia
}

\author{
Anthony R. Lupo, ${ }^{1}$ Igor I. Mokhov, ${ }^{2}$ Merseid G. Akperov, ${ }^{2}$ \\ Alexander V. Chernokulsky, ${ }^{2}$ and H. Athar ${ }^{3}$ \\ ${ }^{1}$ Department of Soil, Environmental, and Atmospheric Sciences, University of Missouri, 302 ABNR Building, Columbia, \\ MO 65211, USA \\ ${ }^{2}$ A.M. Obukhov Institute of Atmospheric Physics, Russian Academy of Sciences, 3 Pyzhevsky, Moscow 119017, Russia \\ ${ }^{3}$ Center of Excellence for Climate Change Research and Department of Meteorology, King Abdulaziz University, P.O. Box 80208, \\ Jeddah 21589, Saudi Arabia \\ Correspondence should be addressed to Anthony R. Lupo, lupoa@missouri.edu
}

Received 21 June 2012; Revised 23 August 2012; Accepted 27 August 2012

Academic Editor: Klaus Dethloff

Copyright ( $) 2012$ Anthony R. Lupo et al. This is an open access article distributed under the Creative Commons Attribution License, which permits unrestricted use, distribution, and reproduction in any medium, provided the original work is properly cited.

During the summer of 2010, an unusually persistent blocking episode resulted in anomalously warm dry weather over the European part of Russia. The excessive heat resulted in forest and peat fires, impacted terrestrial ecosystems, greatly increased pollution in urban areas, and increased mortality rates in the region. Using the National Centers for Atmospheric Research (NCAR), National Centers for Environmental Prediction (NCEP) reanalysis datasets, the climatological and dynamic character of blocking events for summer 2010 and a precursor May blocking event were examined. We found that these events were stronger and longer lived than typical warm season events. Using dynamic methods, we demonstrate that the July 2010 event was a synopticscale dominant blocking event; unusual in the summer season. An analysis of phase diagrams demonstrated that the planetaryscale did not become stable until almost one week after block onset. For all other blocking events studied here and previously, the planetary-scale became stable around onset. Analysis using area integrated regional enstrophy (IRE) demonstrated that for the July 2010 event, synoptic-scale IRE increased at block onset. This was similar for the May 2010 event, but different from case studies examined previously that demonstrated the planetary-scale IRE was prominent at block onset.

\section{Introduction}

Blocking events are generally thought of as quiescent phenomena that bring warmer and drier conditions to the areas that they impact and colder, wetter conditions in the upstream and downstream [1-7]. Their influence on the weather upstream and downstream of the main event, however, is well documented (e.g., [1-7]). They often bring anomalously stable weather conditions (high pressure), and this can result in air pollution events over the regions where they occur (e.g., [8-12]). During the cold season, it is the upstream and downstream regions that are more adversely affected by strong cold waves induced by the blocking event (e.g., $[2,7])$. During the warm season, the regions were covered by the block suffer excessive heat (e.g., $[11,12])$.

The blocking episode that occurred over the European part of Russia during the summer of 2010 was devastating, especially over the western part of the country. It is estimated that more than 50,000 Russian inhabitants perished due to the weather conditions associated with the blocking events (see http://ifaran.ru/science/seminars/Summer2010.html). The mortality rates due to the unprecedented summer heat and air pollution associated with the forest and peat fires were much larger than the normal rates for summer, especially in major urban areas such as Moscow. Additionally, the same blocking episode led to flooding in 
central Europe during the spring [13] and in the Pakistan region downstream of the blocking during the summer [14-16].

The dynamics of blocking events have been examined in previous studies by partitioning the flow into the synopticand planetary-scale [17-22] components. Many studies have shown that the synoptic-scale plays a crucial role in the formation and maintenance of blocking events $[3,18,23-$ $26]$. The role of the planetary-scale has also been discussed recently [27-30]. Few studies, however, have examined the dynamics of blocking decay. In [22], it was proposed that there were four scenarios under which blocking events decayed. There were two scenarios, which are described as an (a) steady-state planetary-scale, or (b) the planetaryscale changing phase or amplitude. Then, each of these scenarios were further classified as either being an (a) passive or (b) active blocking decay depending on the activity and contributions from synoptic-scale upstream cyclones. This builds on [26] who describe a passive decay scenario under which the blocking event is no longer supported by upstream cyclones, or they are too far upstream to contribute. In [26] this is contrasted with a scenario that describes upstream cyclones acting to break down the blocking event, called active here. This work [22] also introduced the use of the phase diagrams and an area-integrated enstrophy index as a tool for examining the dynamics of three Southern Hemisphere winter season blocking events. The blocking area-integrated enstrophy (IRE) is based on the conjecture found in [31]. It was found further in [22] that the IRE decreased during the time the blocking events persisted and increased during large-scale regime transformations. The increase cited in [22] included the time period around the onset and decay of an individual blocking event.

Then, [10] used the IRE as well as a scale partition of this quantity to examine the lifecycle of blocking events during a three-year period across the entire Northern Hemisphere. The IRE was also noted to be a useful tool in identifying large-scale regime changes that corresponded to block formation or decay. Also, a companion diagnostic, the maximum in the gradient of the geostrophic stream function was found to be complimentary to the IRE in identifying block onset or decay [10]. Additionally, the dynamics of a summer season blocking event were studied by utilizing the synoptic and planetary IRE [10]. Then [10] included a method for identifying blocking events as either synoptic or planetary-scale dominant, or of mixed dominance. It was found that most blocking events (79\%) were dominated by a single-scale, either the planetary-scale $(44 \%)$ or synopticscale $(35 \%)$ alone. The rest were of mixed-scale dominance. Furthermore, it was found that there were more planetaryscale dominant blocking events during the warm season.

Thus, the goals of this study are to perform a dynamic study of the blocking events that occurred over the European part of Russia during the spring and summer of 2010. Using the IRE and phase diagrams developed earlier [10, 22], based on the conjecture of [31] and explained in Section 2.2, these blocking events will be studied in order to determine whether they were similar dynamically to previously studied winter and summer season events. Given the strength of the July 2010 event, it is conjectured here that the event may have been more similar to winter season events in a dynamic sense. This would imply that the synoptic-scale was dominant in supporting the July 2010 event and explain the consistent reinforcement of very warm and humid air into the western Russia region. In order to study the importance of the synoptic versus the planetary-scale, the height field was partitioned using methods based on those found in previous studies [18-22]. Such a study is timely and relevant, given the recent occurrence of the event, and there are no other studies (e.g., $[12,30]$ ) that examine this blocking episode in the manner proposed here. Also, this work will further test the utility of the IRE following [10], in particular, does an increase in the IRE indicate the onset or decay of blocking as was postulated in [10]. Additionally, it will be indicated that the source of moisture during these events was of Atlantic origin.

\section{Data and Methods}

2.1. Data. The data set used in this study was the National Center for Environmental Prediction (NCEP) and National Center for Atmospheric Research (NCAR) gridded reanalysis data $[32,33]$. These data were provided on the $2.5^{\circ}$ by $2.5^{\circ}$ latitude-longitude grids available on 17 mandatory levels from $1000 \mathrm{hPa}$ to $10 \mathrm{hPa}$ at $6-\mathrm{h}$ intervals daily at (http://www.esrl.noaa.gov/psd/data/reanalysis/). In this study, the $500 \mathrm{hPa}$ height values were used in order to identify the blocking events and make comparative calculations. The $500 \mathrm{hPa}$ eddy heights were also obtained from this data set and used to represent the synoptic-scale. The $500 \mathrm{hPa}$ eddy heights were derived in the data set by removing the zonal mean from each point at a particular latitude from the daily height field. These data were also similar to the synoptic-scale-scale signal produced by the filtering procedures used in [18-22], thus saving computational resources. The planetary-scale heights were then calculated by subtracting the synoptic-scale heights from the $500 \mathrm{hPa}$ total height field [18-22].

2.2. Methods. The blocking definition and intensity calculation are found in [4] and these are based on the definitions originally proposed by [3]. This definition is a combination of the subjective Rex definition [1], and the objective criterion published in [34]. The criterion of [34] is a calculation of the zonal index (height at $40^{\circ} \mathrm{N}$-height at $60^{\circ}$ $\mathrm{N}$ at $500 \mathrm{hPa}$ ) which is proportional to the geostrophic wind. Where this value is less than zero over 30 degrees longitude and for five or more days indicates blocking. Briefly, the blocking criterion used here includes (i) satisfying the Rex [1] criteria for a minimum of five days; (ii) a negative or small positive zonal index (less than 50 units as suggested by [3]), must be identified on a time-longitude or Hovmöller diagram; (iii) conditions (i) and (ii) satisfied for $24 \mathrm{~h}$ after (before) onset (termination); (iv) the blocking event should be poleward of $35^{\circ} \mathrm{N}$ during its lifetime, and the ridge should have an amplitude of greater than $5^{\circ}$ latitude; and (v) blocking onset is determined to occur when condition 
(iv) and either conditions (i) or (ii) are satisfied, while (vi) termination is designated at the time the event fails condition (v) for a $24 \mathrm{~h}$ period or longer. This procedure is used to detect the blocking events at $500 \mathrm{hPa}$ and defines the blocking duration using these start and end dates.

The blocking intensity (BI) is defined as [4]

$$
\mathrm{BI}=100\left[\left(\frac{Z_{\max }}{Z}\right)-1\right] .
$$

In (1), $Z_{\max }$ is the maximum $500 \mathrm{hPa}$ height in the closed anticyclone region or on a line associated with the ridge, and $Z$ is defined as the mean contour determined from the mean contours upstream and downstream of the block [4]. The upstream and downstream mean contours are calculated by taking the mean of $Z_{\max }$ and the lowest value in the upstream and downstream trough axes. Then, as shown in [4], BI measures the amplitude of the flow around the block.

In this analysis, the onset period is defined as the period before block onset defined above, while intensification (decay) is represented by a general increase (decrease) in center point heights. Maintenance is generally represented by periods where the center point time tendency is close to zero.

In [22], trajectories in the phase plane with the abscissa $X(t)$ and the ordinate $d X(t) / d t$ were analyzed by using a time series for a variable (here $500 \mathrm{hPa}$ height) $X(t)$ analogously to those used in several studies [35-40]. If the regime is cyclical, the process can be fitted by a harmonic oscillator. The trajectories for this oscillator in the phase plane are circular. Then, for stable regimes, the trajectories approach an attractor, in particular, a limit cycle. The attractor regime, generally speaking, may change its character. It should be noted here, in general, that circular trajectories do not necessarily correspond to an attractor. (A trajectory can also exist in the vicinity of the cycle long enough even when the cycle is weakly unstable.) For an unstable regime, the trajectories will spiral outward.

In $[10,22]$, IRE was used and derived from [31], and [31] defined blocking as a meridional perturbation that destabilizes the zonal flow. Starting from the barotropic vorticity equation, the IRE was suggested as a measure for the change in the zonal flow that may lead to the blocking. Here, we make use of the conjecture proposed in [31] which suggests a relationship between the sum of the positive eigenvalues of the linearization operator in the barotropic flow and the blocking domain integrated regional enstrophy, that is from [10]

$$
\sum_{i} \lambda_{i}^{+} \approx \int_{D}|\varsigma|^{2}(y) d x d y,
$$

where $\zeta$ is the vorticity in the horizontal plane and $D$ is defined as the blocking domain. The blocking domain $D$ is defined as a latitude and longitude box encompassing the block center, here $20^{\circ}$ latitude by $20^{\circ}$ longitude. As found by [10] the exact dimensions of the box in the blocking domain were not critical as long as the calculation was in the blocking region (not shown here). Also, the vorticity in (2) is calculated by using the partitioned height fields as described in Section 2.1. Additionally, the right hand side of (2) is called the IRE. In region $D$, higher (lower) positive values of the IRE corresponded to more (less) unstable flow.

The results of [10] also demonstrated that the maximum in the absolute value of the stream function gradient $(\max |\nabla \psi|)$ in the domain $D$ together with the IRE provided more reliable guidance for identifying block onset and termination. Here $\psi=g z / f$, where $f=2 \Omega \sin (\varnothing)$ is the Coriolis parameter. The latitude is denoted by $\varnothing$. The variable $\Omega$ is the rotation of earth $(\Omega$ is $7.292 \times$ $10^{-5} \mathrm{rad} \mathrm{s}^{-1}$ ), and $g$ is the gravitational acceleration. The variable $\psi$ is the total stream function, so the quantity, $\max |\nabla \psi|$ is also the maximum geostrophic wind speed. The behavior of this stability indicator has simple physical meaning. In the case of weak zonal flow, the meridional component will be dominant [10].

In order to determine the scale dominance of a blocking event, the methodology of [10] was used within the domain $D$ for the IRE above and the method is described briefly here. The filtered planetary-scale height $[10,18-22]$ was averaged over $D$, then the synoptic-scale height for each grid point of the domain was calculated by subtracting the planetary-scale from the total height and averaged over $D$. A blocking event was called planetary-scale if, at least, this height averaged over the mature stage of the blocking event is larger than the corresponding monthly mean height value. A similar definition was used for the synoptic-scale. If the blocking event occurred within two months, the scale contribution dominance was determined by comparing the behavior of the averaged heights relative to the two-month mean value. The monthly mean was chosen simply to provide a zero reference point from which to assess which scale was prominent during the lifecycle of the event [10]. Based on the above criterion for comparison of heights, the blocking events are categorized into the following three types: (i) planetary-scale height dominant events, (ii) synoptic-scale height dominant events, and (iii) alternating-scale height dominant events [10]. In [10], scale dominance refers to the relative strength of the height or flow associated with the blocking event during its entire lifecycle.

\section{Climatological and Synoptic Analysis}

During the summer of 2010, a blocking episode persisted from 19 June to 19 August, 2010 over Eastern Europe and the European part of Russia using the definition in Section 2 and resulting in anomalously warm and dry conditions over the region. These dates include the formation period of the June blocking event and days following the eventual termination of the August event. A comparison of the monthly mean values for temperatures and precipitation for summer 2010 relative to the mean values from 1970-2010 is given in Table 1 for May through August in Moscow. If one standard deviation from the mean represents unusual conditions [41], then May was unusually warm in the Moscow region while the July and August temperatures were unprecedented and represented the extreme values for the 41-year period cited above (and also for the longer period of record). 
Table 1: The temperature $\left({ }^{\circ} \mathrm{C}\right)$ and precipitation $(\mathrm{mm})$ for MayAugust 2010 for the Moscow, Russia. In the right column, the precipitation anomaly is expressed as a $\%$ of normal.

\begin{tabular}{lccc}
\hline Month & $\begin{array}{c}\text { Normal } \\
\left({ }^{\circ} \mathrm{C} / \mathrm{mm}\right)\end{array}$ & $\begin{array}{c}\text { Observed } \\
\left({ }^{\circ} \mathrm{C} / \mathrm{mm}\right)\end{array}$ & $\begin{array}{c}\text { Anomaly } \\
\left({ }^{\circ} \mathrm{C} / \mathrm{mm}[\%]\right)\end{array}$ \\
\hline May & $13.0 / 51.8$ & $16.8 / 59.0$ & $+3.8 /+7.2[113.9]$ \\
June & $16.9 / 78.2$ & $18.7 / 62.0$ & $+1.8 /-16.2[79.3]$ \\
July & $18.9 / 86.3$ & $25.7 / 12.0$ & $+6.8 /-74.3[13.9]$ \\
August & $16.8 / 79.6$ & $22.0 / 68.0$ & $+5.2 /-11.6[85.4]$ \\
\hline
\end{tabular}

While the summer period was dry, only July was unusually dry in the Moscow region.

Three distinct blocking events meeting the criterion described in Section 2.2 are given in Table 2 along with their characteristics. Also, provided in Table 2 is information about a persistent event which dominated the region for the month of May (event 1) and this event is referred to as a precursor blocking event. With the exception of the May event (block 1), all were weaker than a typical blocking event, and each persisted longer than a typical event except for event number two. The July event (event 3 ) persisted for 26 days, which means it is one of the most persistent events for the Northern Hemisphere since 1970 (see [4]). While each event was weaker than a typical event, they were stronger than the average summer season event with the exception of the June event. Additionally, studies by $[29,42]$ identified the blocking episode as occurring from mid-to-late June to early-to-midAugust using a different blocking definition (see also [11]).

The duration of the blocking circulations in Table 2 was persistent enough that the May (event 1) and July (event 3) events can be identified in the monthly mean $500 \mathrm{hPa}$ height field in the Northern Hemisphere (Figures 1(a) and 1(c)). In Figure 1, a ridge appears over western Russia in each panel and is characterized by split flow. Each of these met the blocking criterion of [4]. During May and July, a blocking ridge appears over extreme eastern Russia as well (Figures 1(a) and 1(c)). These ridges in eastern Russia were also associated with blocking events (see the blocking archive at http://weather.missouri.edu/gcc), but these events were not studied here.

Additionally, the monthly mean precipitable water for July 2010 (Figure 2(a)) suggests that the high relative humidity and dew point that were associated with the July heat were likely due to moisture not only from the Mediterranean and the Black Sea, but also from the Atlantic Ocean region. Precipitable water $(\mathrm{PW})$ is shown here since it is the column integrated value of specific humidity $(q)\left(\mathrm{kg} \mathrm{kg}^{-1}\right)$

$$
\mathrm{PW}=\frac{1}{g} \int_{\mathrm{psfc}}^{\mathrm{ptrop}} q d p
$$

where $g$ is the gravitation constant, and $q$ is integrated from the surface to the tropopause. The jet stream over Europe was quite active and resulted in wet conditions for central Europe in May and June as shown in [13]. During July, a moisture plume can be seen connecting Atlantic moisture to the western Russia region, via Western Europe (Figure 2(a)). Figure 2(b) shows the precipitable water anomalies relative to climatology in the NCEP reanalyses, and positive anomalies resided over Western Europe through western Russia coincident with the high precipitable water in Figure 2(a). Note in Figure 2(b), warm colors are positive anomalies. This result would be consistent with [6] who showed that European blocking can ingest moisture from across the northern Atlantic. Figure 2(c) also shows the observed total zonal momentum flux anomaly for July 2010, which was an available quantity. Note that the total zonal momentum flux anomaly was a maximum on the upstream flank of the block in Figure 1 over Eastern Europe and western Russia, and this was likely associated with the upstream cyclones sustaining the block. This result is consistent with earlier studies [18-20, 24, 25, 30], and these transients would also be carrying energy and water vapor into the region.

These blocking events were then examined following [10] in order to determine whether or not they were dominated by either the planetary-scale, synoptic-scale, or were alternating-scale dominant events (Table 3 ). The results here are consistent with the climatological behavior elucidated in [10] in that only one of these blocking events were alternating in their scale dominance, while the May (event 1-spring) and August (event 4-summer) events were dominated by the synoptic and planetary-scale, respectively. In [10], spring (summer) blocking event were synoptic (planetary-) scale dominant in $45 \%(55 \%)$ of events. The July block (event 3), however, was dominated by the synoptic-scale (Figure 3), and [10] showed that it is more unusual for the synoptic-scale to dominate during this season. The summer season case study examined in [10] was a planetary-scale dominant event. The previous work of $[10,19]$ demonstrated that the planetary-scale forcing was a larger contributor in the summer season, while the synoptic-scale forcing from upstream cyclones was more prominent during the winter season. Thus, the dynamics of the July 2010 event in the context of [10] warrants closer examination.

Further, for the July 2010 block (event 3), the time series of the total center point heights correlate very strongly to the planetary-scale center point heights (correlation coefficients greater than 0.95), while the synoptic-scale center point heights correlate to the total and planetary-scale at 0.62 , and 0.60 , respectively (Figure 3 ). This is significant at the $95 \%$ confidence level (using the Pearson test for the significance of the correlation coefficient). The correlation calculations for the two longer-lived blocking events (May (event 1) and August (event 4) from this blocking episode (Table 2) yielded a similar result (not shown). The center point 24-hour height tendencies were then calculated for each blocking event, and these were also partitioned into their planetaryscale and synoptic-scale height tendencies. The correlation between the total and planetary-scale height tendencies was significant at the 95\% confidence level as well for the three long-lived events (Table 2), and the correlations ranged from 0.52 to 0.60 . The planetary and synoptic-scale height tendencies correlated negatively at the $95 \%$ confidence level for the same events, and these ranged from -0.66 to -0.81 . There was no correlation between the total height tendencies and the synoptic height tendencies except for the July block (event 3 ) in which these two scales correlated positively 
TABLE 2: The blocking events studied here and their characteristics such as duration, intensity, and formation longitude, where $S$ is the mean summer season event and $T$ is the climatological mean event from [4].

\begin{tabular}{lcccc}
\hline Event & Onset/Termination & Duration (days) & Intensity $(\mathrm{BI}=\mathrm{m} / \mathrm{m})$ & Formation (longitude) \\
\hline 1 & 1200 UTC 2 May/0000 UTC 24 May & 21.5 & 3.08 & $40 \mathrm{E}$ \\
2 & 0000 UTC 22 June/0000 UTC 28 June & 6.0 & 1.69 & $50 \mathrm{E}$ \\
3 & 0000 UTC 4 July/0000 UTC 30 July & 26.0 & 2.44 & $20 \mathrm{E}$ \\
4 & 1200 UTC 31 July/0000 UTC 16 August & 15.5 & 2.50 & $45 \mathrm{E}$ \\
$S$ & N/A & 7.6 & 2.13 & N/A \\
$T$ & N/A & 8.2 & 3.04 & N/A \\
\hline
\end{tabular}

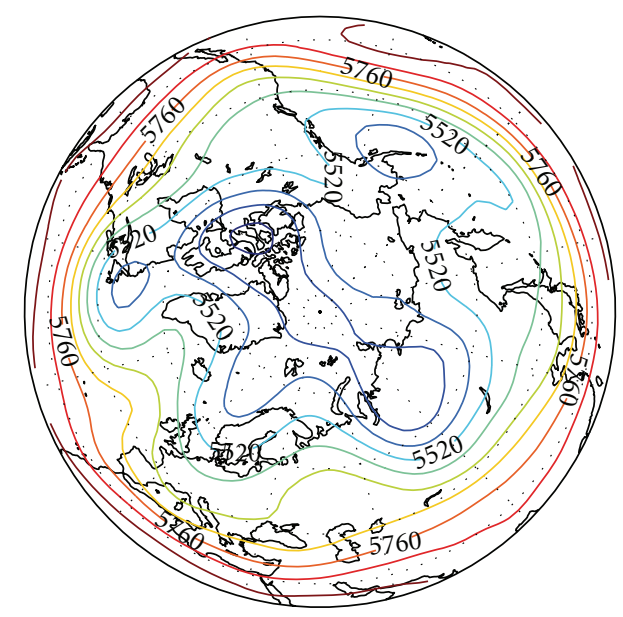

(a)

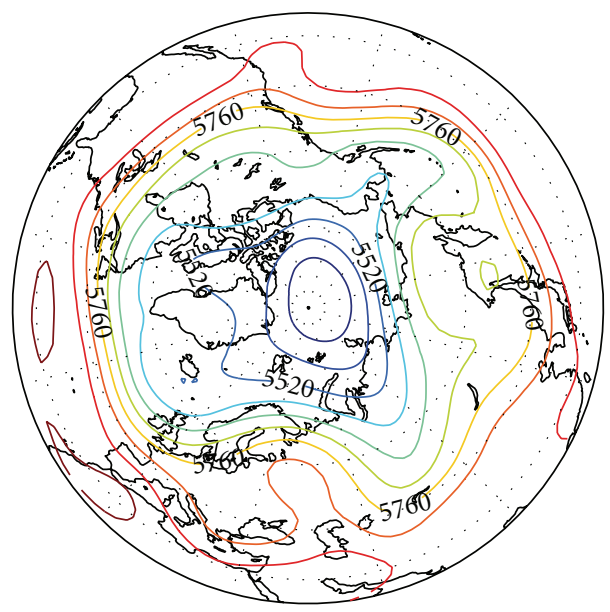

(c)

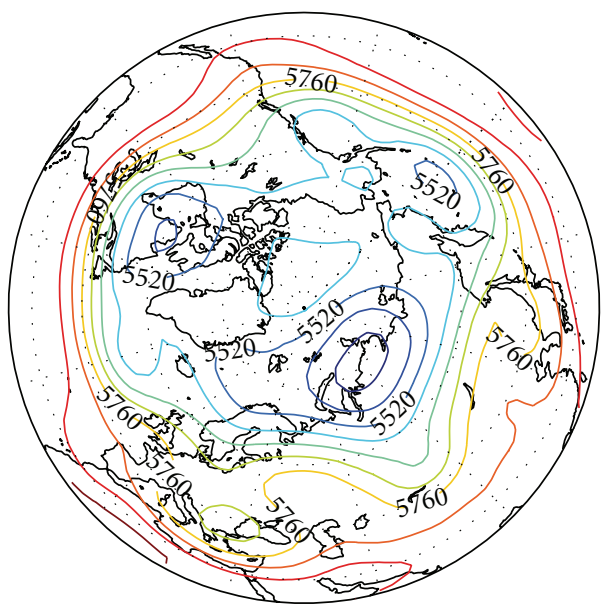

(b)

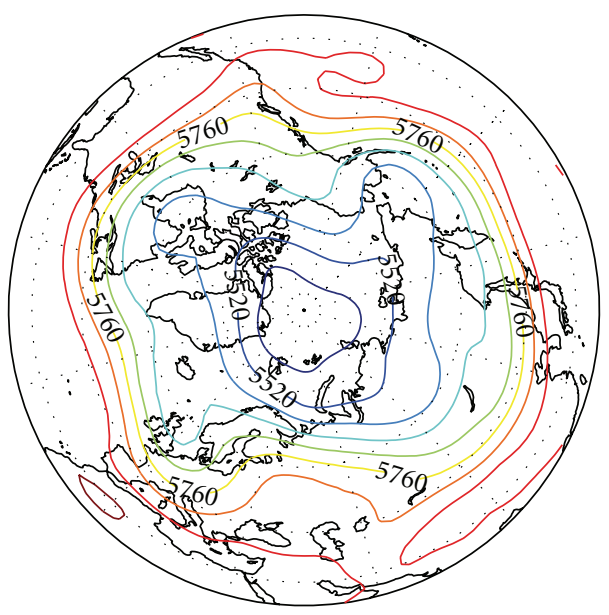

(d)

Figure 1: The NCEP-NCAR reanalyses for the Northern Hemisphere $500 \mathrm{hPa}$ heights for (a) May, (b) June (20-30), (c) July, and (d) August (1-20), 2010. The contour interval is $60 \mathrm{dam}$.

(0.30) at the $90 \%$ confidence level. This provides further evidence that this blocking event is not a typical summer season event.

\section{Dynamic Analysis}

The climatological and synoptic analysis demonstrated that the July 2010 blocking event was unusual in that it was stronger and longer lived than a typical summer season event. Using the analysis for scale dominance proposed by [10], this event was also unusual in that it was a synoptic-scale dominant summer event. Thus, using the techniques developed by [22], the July and August events will be examined in more detail here in order to provide a comparison between synoptic, and planetary-scale dominant summer season events. The May and June events were also examined for comparison, and the dynamics were both similar to the events analyzed in [22], and consistent with the results of previous blocking studies. 


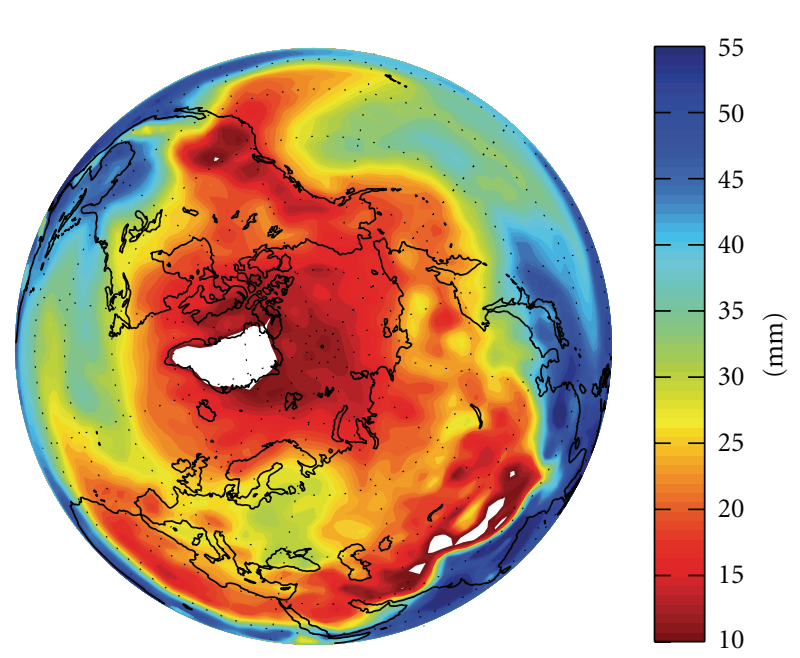

(a)

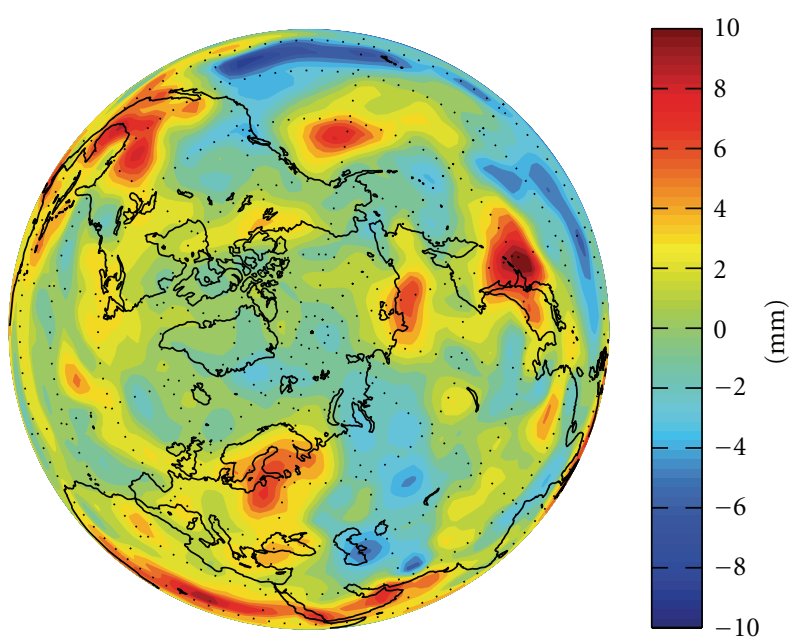

(b)

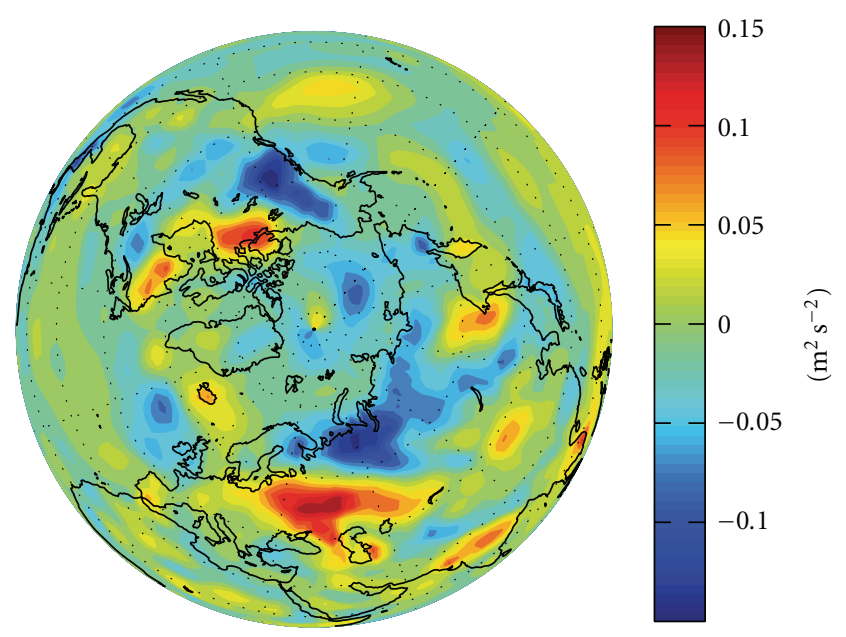

(c)

Figure 2: The Northern Hemisphere (a) precipitable water ( $\mathrm{mm}$ ), (b) precipitable water anomalies (mm), and (c) zonal momentum flux $\left(\mathrm{m}^{2} \mathrm{~s}^{-2}\right)$ anomaly for July 2010, the climatological reference period is 1981-2010. In (b) and (c) positive (negative) numbers indicate more (less) moisture or zonal momentum flux than the mean and are represented by warm (cool) colors.

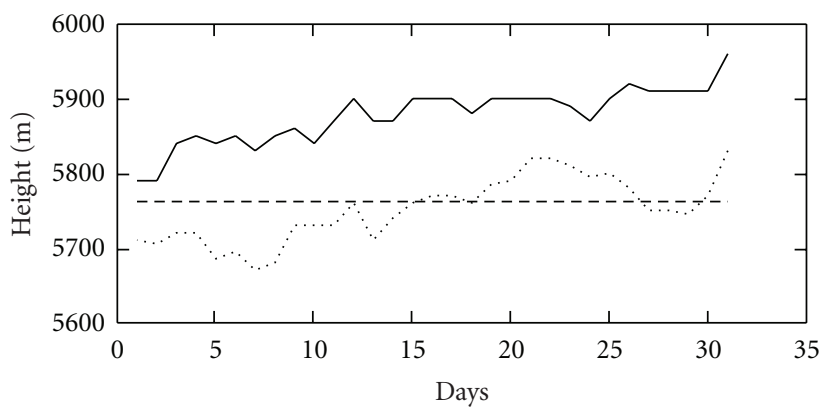

(a)

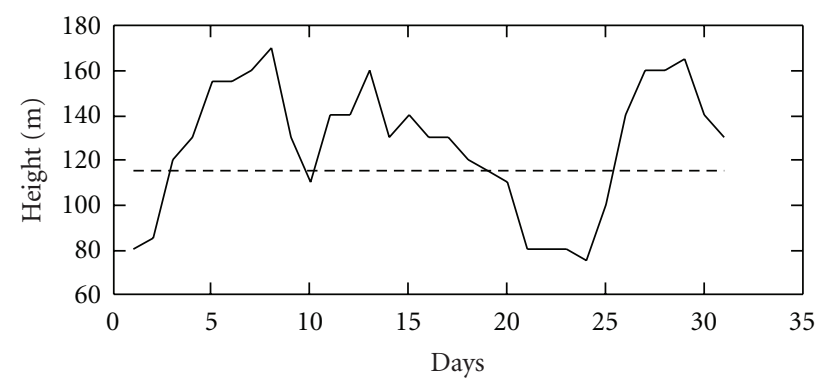

(b)

FIGURE 3: The block center region height ( $\mathrm{m}$ ) for July 2010 following [10] showing (a) the total height field (solid) and planetary-scale height (dots), and (b) synoptic-scale height (solid). The horizontal straight lines show the monthly mean, (a) planetary-scale, and (b) synoptic-scale heights. 
TABLE 3: Scale dominance for the spring and summer 2010 blocking events studied here following the methodology of [10].

\begin{tabular}{lcc}
\hline Event & Planetary-scale dominant & Synoptic-scale dominant \\
\hline 1 & Negative & Positive \\
2 & Alternating & Alternating \\
3 & Negative & Positive \\
4 & Positive & Negative \\
\hline
\end{tabular}

In [22], phase diagrams were constructed by plotting the blocking region planetary-scale $500 \mathrm{hPa}$ height tendencies for two Southern Hemisphere winter season events. Here the same technique is applied to the Northern Hemisphere summer season events, and the synoptic-scale $500 \mathrm{hPa}$ heights over the block region are examined as well. Figures 4 and 5 show these phase diagrams for the July and August events. The May and June blocking events were consistent with the results of [22] for both scales (not shown).

Note in Table 2, the July and August blocking events occur in a similar area, and that the decay of the July event overlaps with the onset of the August event. This behavior is similar to that of two cases studied in [22]. Correspondingly, the trajectory end in Figure 4 overlaps with the beginning of that in Figure 5. In Figure 4, the planetaryscale was more unstable during the first six days of the block lifecycle, or longer after block onset, and then becomes more stable for about 10 days. In these diagrams, an unstable (stable) trajectory is one that moves or spirals away from (toward) some defined point, while in an oscillatory system the trajectories would be circular (e.g., [22, 43]). During the last ten days, the planetary-scale again becomes unstable. In [22], and for the May and June event here, the planetaryscale trajectory indicated that the flow becomes stable at the time of block onset. However, the planetary-scale does move to a new regime before block termination in a fashion similar to the two consecutively occurring blocking events in [22]. Then Figure 5(a) shows that the planetary-scale flow finds a new equilibrium during the second blocking event. This equilibrium persists until the decay of the August block. Figure 3(a) shows planetary-scale heights that are increasing over the life-time of the July event, while the planetary-scale flow during the August event was stable (no trend) until the final days of the blocking episode (not shown). The synoptic-scale trajectories (Figures 4(b), and 5(b)) demonstrate stability for this scale in the blocking region after the onset of the July event and then remaining in quasi equilibrium until the decay of the August event.

The IRE was examined as following [22] and partitioned by [10] and is shown in Figure 6. In [10], it was conjectured that the IRE showed some promises as an indicator of flow regime change, and that there was a tendency for the IRE to increase near the block onset and again before the block decay. The results of [22] suggested that the IRE was lower (higher) when the flow was stable (unstable). In this context (Figure 6), a stable (unstable) flow is related to regime change and the relative strength of the IRE. Note also in Figure 6, that for each event, the synoptic-scale IRE is relatively large (small) for the synoptic (planetary-scale) height dominant events. In the short-lived alternating-scale event of June, it is difficult to determine whether the synoptic-scale IRE values are relatively large compared to the planetary-scale.

In [31], a minimum in the area integrated enstrophy is associated with a regime that is quasi-barotropic and blocking. A minimum in this quantity also implies a greater degree of predictability. Here it is found that the planetaryscale IRE increases at or close to onset time and then decreases during the maintenance phase (after onset) for the August event (Figure 6(d)). For the June event (Figure 6(b)), the planetary-scale increases just after onset, but increases throughout the short lifecycle of the event with a local maximum near the termination time.

However, for the July event (Figure 6(c)), the synopticscale IRE indicated unstable flow at block onset and then remains relatively low for the rest of the event increasing slightly again near decay. During the May event (Figure 6(a)), the synoptic-scale IRE increased at onset and increased again substantially near decay. In both the May and July events (Figures 6(a) and 6(c)), the planetary-scale IRE indicates stable flow during the first part of the event following along with the unstable synoptic-scale flow. Then for both the planetary-scale becomes unstable during the lifecycle and ultimately becoming smaller through decay. This behavior contrasts with the August event above and the summer season event shown in [10]. Additionally, when using the maximum in the gradient of the geostrophic stream function as a diagnostic partner following [10], Figure 7 demonstrates that for July 2010 this quantity also showed a relative maximum at onset in the synoptic-scale field. The synopticand planetary-scale both increase near decay in Figure 7. This diagnostic showed similar results to the IRE for the other events (not shown) as in [10].

The above paragraph suggests that when using the IRE diagnostic, the May and July 2010 blocking event behaved in a different manner. It is suggested here that in synopticscale dominant events, the increase in the synoptic-scale IRE may play the key role in indicating block formation and decay, while in planetary-scale dominant and alternatingscale events, the planetary-scale IRE may be a better indicator of block onset. This finding refines the conclusions of [10] who studied a planetary-scale dominant event. Note, however, in the alternating-scale event (June), both scales reached a maximum close to onset time.

The correlation between the total IRE and the planetaryscale IRE was greater than 0.68 for all cases, and this was significant at the $99 \%$ confidence level. However, there was no correlation between the synoptic-scale IRE and either the total on planetary-scale IRE. Additionally, as a synoptic-scale dominant event, the July 2010 event was different from the event studied by [10] but behaved similar to the summer season event studied in [20]. Also, here, it is suggested that, the synoptic-scale played the dominant role in determining onset and the decay in the July 2010, and this is similar to the result found for the Southern Hemisphere winter events in [21].

New results published recently [42] showed that, by using several medium range operational ensemble forecasts, the predictability of blocking has improved to the point that 


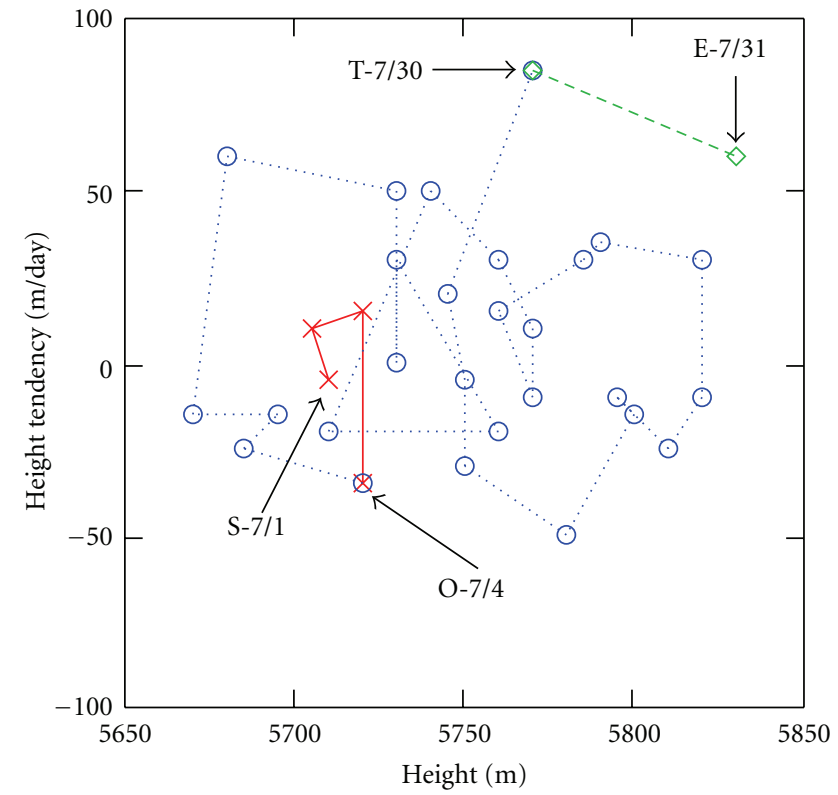

(a)

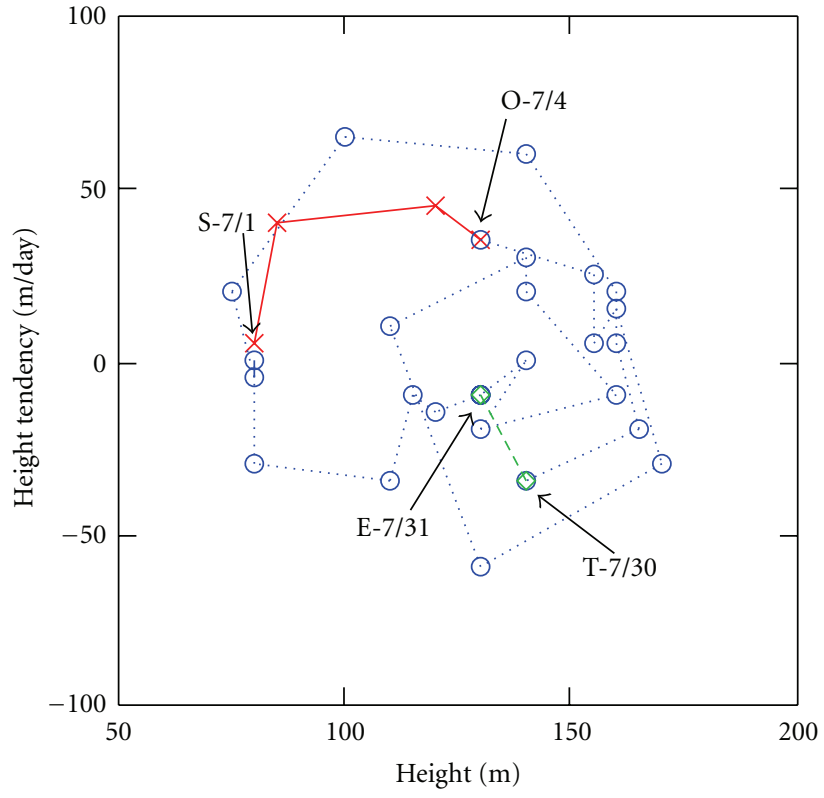

(b)

FIgURE 4: Phase trajectories for the 500-hPa heights in the central part of the blocking region for July 2010 for the (a) planetary-scale, and (b) synoptic-scale, during the preblock (solid, red-X), the block lifecycle (dots, blue-o), and decay (dash, green-diamond). The trajectory begins at $(\mathrm{S})$ and ends with $(\mathrm{E})$, and the block onset is marked with $(\mathrm{O})$ and termination with $(\mathrm{T})$. The dates are labeled as month/day.

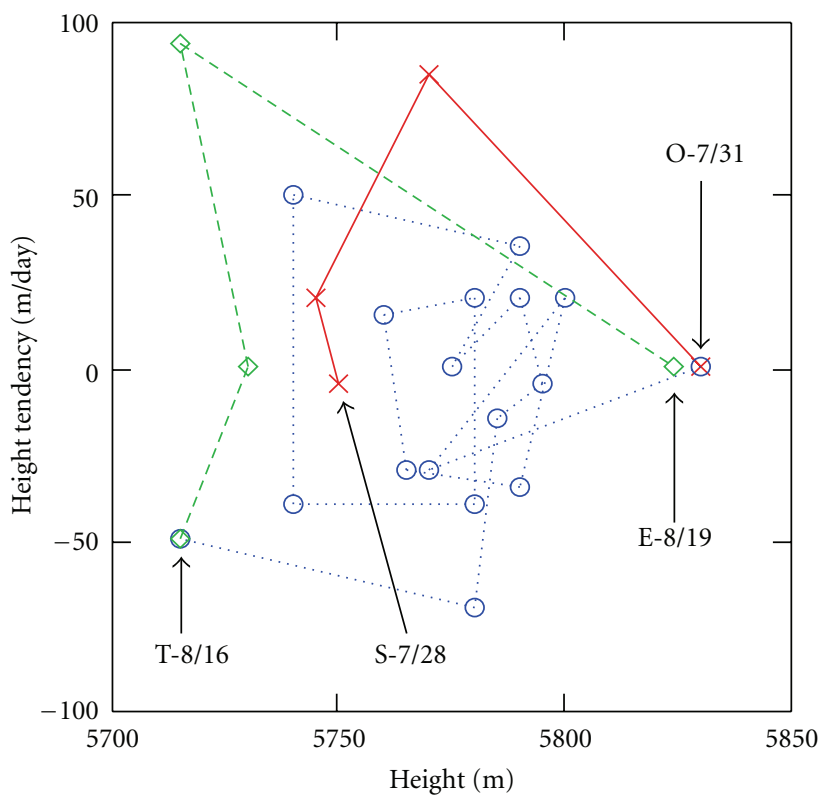

(a)

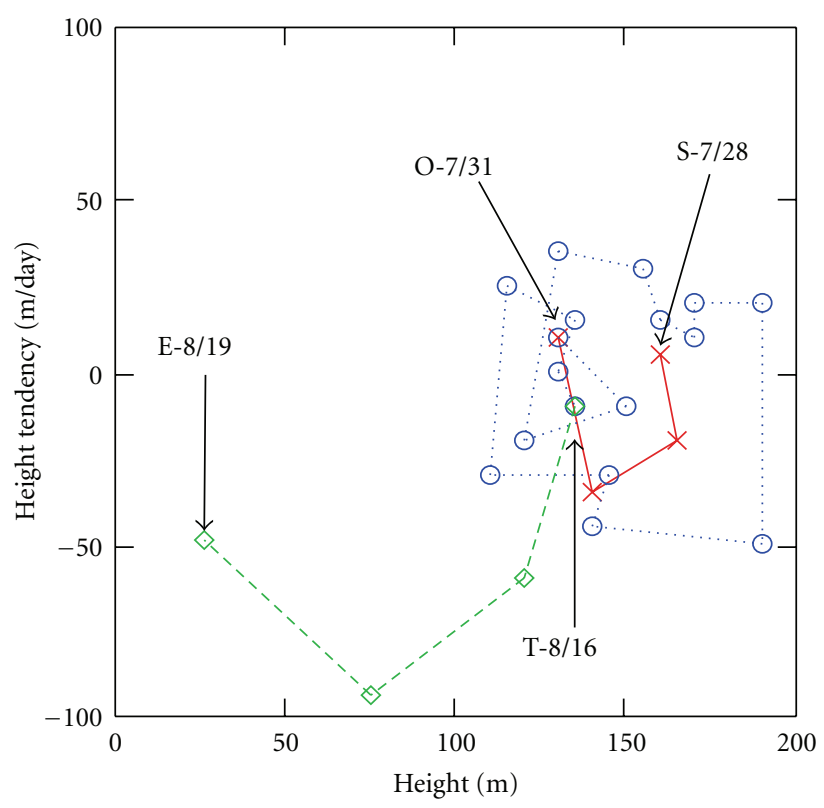

(b)

Figure 5: As in Figure 4, except for the August 2010 blocking event.

the events studied here were predicted very well even at 144$216 \mathrm{~h}$ before onset. Of the events studied here, the August event was the least predictable in [42] at medium ranges. The models all predicted decay too early in each of them [42]. If the results of this study are an indication, onset is easier to predict as the IRE and phase diagrams indicate block onset very close to that identified using the criterion of [4].
As indicated above, the onset of the August event was least predictable [42]. The models also forecast the decay of the July blocking event too early in [42]. Here, the August blocking event followed the July event in rapid succession similar to the blocking events studied in [22]. Thus, it may indicate that models have difficulty with forecasting the decay of one blocking event and the onset of another so close 


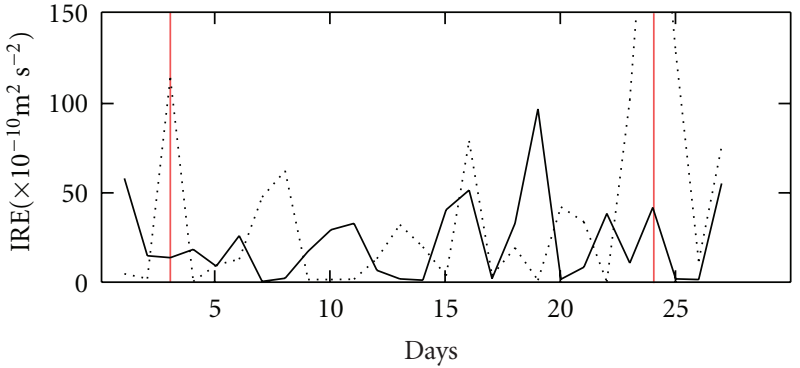

(a)

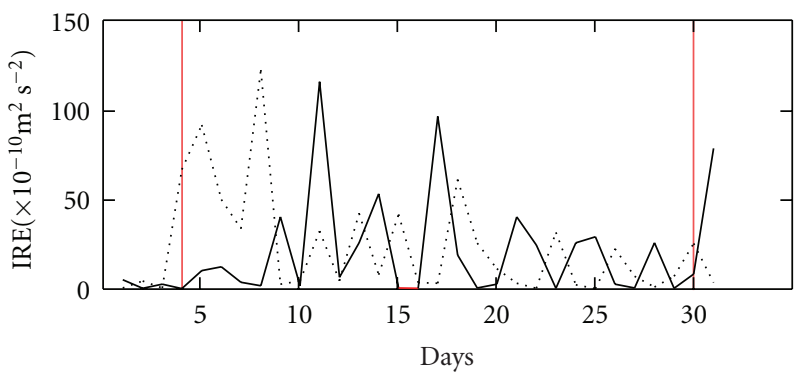

(c)

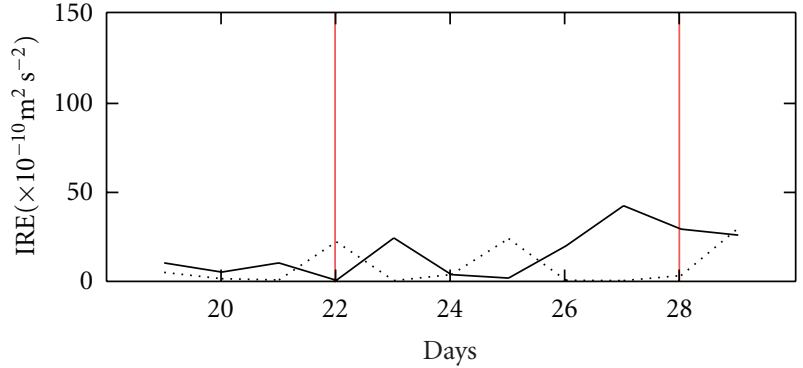

(b)

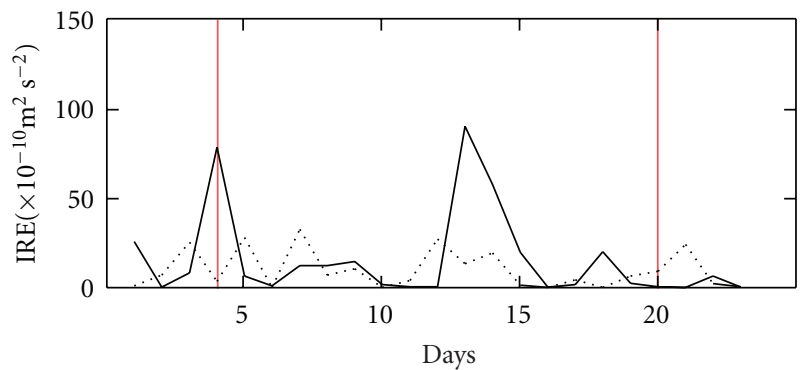

(d)

Figure 6: The IRE $\left(\times 10^{-10} \mathrm{~m}^{2} \mathrm{~s}^{-2}\right)$ for the (a) May, (b) June, (c) July, and (d) August 2010 blocking event where the solid line is the planetaryscale IRE (left ordinate) and the dotted line is the synoptic-scale IRE (right ordinate). The left (right) vertical line represents block onset (termination).

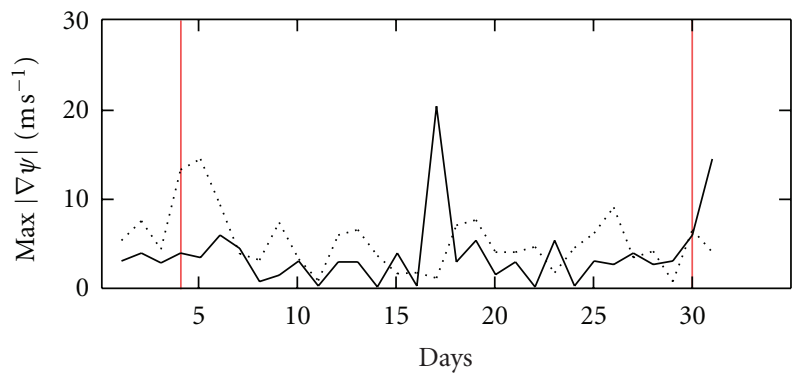

Figure 7: As in Figure 6, except for the maximum $|\nabla \psi|\left(\mathrm{m} \mathrm{s}^{-1}\right)$ calculated following [10] for July 2010 in the blocking domain $D$.

together in time and space. While the model had difficulty forecasting the August event, the IRE increased strongly at the start of this event again showing the utility of the IRE for indicating block onset.

\section{Summary and Conclusions}

The blocking events that impacted the European part of Russia bringing anomalously high temperatures during the summer of 2010 were studied here. These events resulted in many deaths and devastating forest and peat fires in the European part of Russia, including the Moscow region. This study identified the blocking episode using the NCARNCEP $500 \mathrm{hPa}$ heights archived in Boulder, CO. Using the criterion of [4], three distinct blocking events occurring from late June to mid-August were identified. Additionally, a precursor blocking event which occurred in May 2010 over the same region was included in this study. These events were, in general, more persistent than typical blocking events for spring or summer seasons. These blocking events were weaker than a typical blocking event, but stronger than warm season events when comparing to the climatology of [4].

Examining the dynamics using techniques developed by [22] and further refined by [10] shows that, in many respects, the dynamics of these blocking events were similar to that of previously studied events. However, some important results emerged here. First, the phase diagrams developed by [22] were partitioned into planetary and synoptic-scale components here. The July 2010 blocking event showed that the planetary-scale became stable more than six days after block onset. The other events, as well as those studied previously, became stable at or just following onset. This is the only one of seven events studied here and in [22] that exhibits this behavior, and, thus, the flow becoming stable many days after onset may be fairly uncommon.

Second, examining the IRE developed by [22] and modified by [10] demonstrated that the May and July event 
studied here showed synoptic-scale dominance, and the synoptic-scale IRE increased markedly at onset followed by an increase in the planetary-scale IRE. The IRE then decreased and stayed low until decay. Also, in both of these events, the synoptic-scale IRE was relatively large for each event. This behavior is different from that suggested by [10] which showed that for a planetary-scale block, the planetaryscale increase of IRE at onset was an important indicator of flow transformation to the blocking state. Thus, the results here refine the conclusions of [10] and the synoptic-scale IRE can also be an indicator of block onset in a synopticscale dominant event. Finally, our results here can be used to demonstrate that although predictability by operational models failed in forecasting the August event, which followed rapidly behind the July event, the IRE did indicate the onset of blocking.

\section{Acknowledgments}

The authors would like to thank the three anonymous reviewers for their helpful comments in improving this paper. This research has been supported by the Civilian Research and Development Foundation under Grant RUG12953-MO-09, by the Russian Foundation of Basic Research under Grant 09-05-92505, and by the Russian Ministry of Education and Science under Contract 11.519.11.5004.

\section{References}

[1] D. F. Rex, "Blocking Action in the middle troposphere and its effect on regional climate (II). The Climatology of Blocking Action," Tellus, vol. 2, pp. 275-301, 1950.

[2] R. S. Quiroz, "The climate of the 1983-84 winter-a season of strong blocking and severe cold in North America," Monthly Weather Review, vol. 112, no. 9, pp. 1894-1912, 1984.

[3] A. R. Lupo and P. J. Smith, "Climatological features of blocking anticyclones in the Northern Hemisphere," Tellus, Series A, vol. 47, no. 4, pp. 439-456, 1995.

[4] J. M. Wiedenmann, A. R. Lupo, I. I. Mokhov, and E. A. Tikhonova, "The climatology of blocking anticyclones for the Northern and Southern Hemispheres: block intensity as a diagnostic," Journal of Climate, vol. 15, no. 23, pp. 3459-3473, 2002.

[5] D. Barriopedro, R. García-Herrera, A. R. Lupo, and E. Hernández, "A climatology of Northern Hemisphere blocking," Journal of Climate, vol. 19, no. 6, pp. 1042-1063, 2006.

[6] M. Croci-Maspoli and H. C. Davies, "Key dynamical features of the 2005/06 European winter," Monthly Weather Review, vol. 137, no. 2, pp. 664-678, 2009.

[7] J. Sillmann, M. C. Mischa, M. Kallache, and R. W. Katz, "Extreme cold winter temperatures in Europe under the influence of North Atlantic atmospheric blocking," Journal of Climate, vol. 24, no. 22, pp. 5899-5913, 2011.

[8] G. M. Agayan and I. I. Mokhov, "Quasistationary autumn regimes of the Northern Hemisphere atmosphere in FGGE," Izvestiya, Atmospheric and Oceanic Physics, vol. 25, pp. 115011156, 1989.

[9] I. I. Mokhov, A. V. Chernokulsky, and I. M. Shkolnik, "Regional model assessments of fire risks under global climate changes," Doklady Earth Sciences, vol. 411, no. 9, pp. 14851488, 2006.
[10] H. Athar and A. R. Lupo, "Scale and stability analysis of blocking events from 2002-2004: a case study of an unusually persistent blocking event leading to a heat wave in the Gulf of Alaska during August 2004," Advances in Meteorology, vol. 2010, Article ID 610263, 15 pages, 2010.

[11] N. F. Elansky, I. I. Mokhov, I. B. Belikov et al., "Gaseous composition of surface air in Moscow during the extreme summer 2010," Doklady Earth Sciences, vol. 437, pp. 90-96, 2011.

[12] R. Dole, M. Hoerling, J. Perlwitz et al., "Was there a basis for anticipating the 2010 Russian heat wave?" Geophysical Research Letters, vol. 38, no. 6, Article ID L06702, 5 pages, 2011.

[13] P. Bissolli, K. Friedrich, J. Rapp, and M. Ziese, "Flooding in eastern central Europe in May 2010-reasons, evolution and climatological assessment," Weather, vol. 66, no. 6, pp. 147153, 2011.

[14] P. Webster, V. E. Toma, and H.-M. Kim, "Were the 2010 Pakistan floods predictable?" Geophysical Research Letters, vol. 38, Article ID L04806, 5 pages, 2011.

[15] R. A. Houze, K. L. Rasmussen, S. Medina, S. R. Brodzik, and U. Romatschke, "Anomalous atmospheric events leading to the summer 2010 floods in Pakistan," Bulletin of the American Meteorological Society, vol. 92, no. 3, pp. 291-298, 2011.

[16] C.-C. Hong, H.-H. Hsu, N.-H. Lin, and H. Chiu, "Roles of European blocking and tropical-extratropical interaction in the 2010 Pakistan flooding," Geophysical Research Letters, vol. 38, no. 13, Article ID L13806, 6 pages, 2011.

[17] M. S. Tracton, "Predictability and its relationship to scale interaction processes in blocking," Monthly Weather Review, vol. 118, no. 8, pp. 1666-1695, 1990.

[18] A. R. Lupo and P. J. Smith, "Planetary and synoptic-scale interactions during the life cycle of a mid-latitude blocking anticyclone over the North Atlantic," Tellus, Series A, vol. 47, pp. 575-596, 1995.

[19] A. R. Lupo, "A diagnosis of two blocking events that occurred simultaneously in the midlatitude Northern Hemisphere," Monthly Weather Review, vol. 125, no. 8, pp. 1801-1823, 1997.

[20] A. R. Lupo and P. J. Smith, "The interactions between a mid-latitude blocking anticyclone and synoptic-scale cyclones occurring during the Northern Hemisphere summer season," Monthly Weather Review, vol. 126, pp. 503-5515, 1998.

[21] J. P. Burkhardt and A. R. Lupo, "The planetary- and synopticscale interactions in a southeast Pacific blocking episode using PV diagnostics," Journal of the Atmospheric Sciences, vol. 62, no. 6, pp. 1901-1916, 2005.

[22] A. R. Lupo, I. I. Mokhov, S. Dostoglou, A. R. Kunz, and J. P. Burkhardt, "Assessment of the impact of the planetary scale on the decay of blocking and the use of phase diagrams and enstrophy as a diagnostic," Izvestiya, Atmospheric and Ocean Physics, vol. 43, no. 1, pp. 45-51, 2007.

[23] E. Kalnay-Rivas and L. O. Merkine, "A simple mechanism for blocking," Journal of the Atmospheric Sciences, vol. 38, no. 10, pp. 2077-2091, 1981.

[24] S. L. Mullen, "Transient eddy forcing of blocking flows," Journal of the Atmospheric Sciences, vol. 44, no. 1, pp. 3-22, 1987.

[25] Chih-Hua Tsou and P. J. Smith, "The role of synoptic/ planetary-scale interactions during the development of a blocking anticyclone," Tellus, Series A, vol. 42, no. 1, pp. 174193, 1990.

[26] A. R. Lupo and L. F. Bosart, "An analysis of a relatively rare case of continental blocking," Quarterly Journal of the Royal Meteorological Society, vol. 125, no. 553, pp. 107-138, 1999. 
[27] K. Haines and A. J. Holland, "Vacillation cycles and blocking in a channel," Quarterly Journal of the Royal Meteorological Society, vol. 124, no. 547, pp. 873-895, 1998.

[28] S. J. Colucci and D. P. Baumhefner, "Numerical prediction of the onset of blocking: a case study with forecast ensembles," Monthly Weather Review, vol. 126, no. 3, pp. 773-784, 1998.

[29] D. E. Tilly, A. R. Lupo, C. J. Melick, and P. S. Market, "Calculated height tendencies in two southern hemisphere blocking and cyclone events: the contribution of diabatic heating to block intensification," Monthly Weather Review, vol. 136, no. 9, pp. 3568-3578, 2008.

[30] A. Schneidereit, S. Schubert, P. Vargin et al., "Large scale flow and the long-lasting blocking high over Russia," Monthly Weather Review, vol. 140, no. 9, pp. 2967-2981, 2012.

[31] V. P. Dymnikov, Y. V. Kazantsev, and V. V. Kharin, "Information entropy and local Lyapunov exponents of barotropic atmospheric circulation," Izvestiya, Atmospheric and Oceanic Physics, vol. 28, no. 6, pp. 425-432, 1993.

[32] E. Kalnay, M. Kanamitsu, R. Kistler et al., "The NCEP/NCAR 40-year reanalysis project," Bulletin of the American Meteorological Society, vol. 77, no. 3, pp. 437-471, 1996.

[33] R. Kistler, E. Kalnay, W. Collins et al., "The NCEP-NCAR 50year reanalysis: monthly means CD-ROM and documentation," Bulletin of the American Meteorological Society, vol. 82, no. 2, pp. 247-267, 2001.

[34] H. Lejenas and H. Okland, "Characteristics of Northern Hemisphere blocking as determined from a long time series of observational data," Tellus, Series A, vol. 35, no. 5, pp. 350$362,1983$.

[35] I. I. Mokhov, "Climate changes: analysis of global cycles," Annales Geophysicae, vol. 11, p. 334, 1993.

[36] I. I. Mokhov, Mathematics and Physics [Doctoral Dissertation], IAP RAS, Moscow, Russia, 1995.

[37] I. I. Mokhov and A. V. Eliseev, "Changes in the characteristics of the quasi-biennial oscillation of zonal wind and temperature in the equatorial lower stratosphere," Izvestiya, Atmospheric and Ocean Physics, vol. 34, no. 3, pp. 291-299, 1998.

[38] I. I. Mokhov, A. V. Eliseev, and D. V. Khovorost'yanov, "Evolution of the characteristrics of interannual climate variability associated with the El Niño and La Niña phenomena," Izvestiya, Atmospheric and Ocean Physics, vol. 36, no. 6, pp. 681-690, 2000.

[39] I. I. Mokhov, D. V. Khvorostyanov, and A. V. Eliseev, "Decadal and longer term changes in El Niño-southern Oscillation characteristics," International Journal of Climatology, vol. 24, no. 4, pp. 401-414, 2004.

[40] A. V. Fedorov, S. L. Harper, S. G. Philander, B. Winter, and A. Wittenberg, "How predictable is El Niño?" Bulletin of the American Meteorological Society, vol. 84, no. 7, pp. 911-919, 2003.

[41] A. R. Lupo, E. P. Kelsey, E. A. McCoy et al., "The presentation of temperature information in television broadcasts: what is normal?" National Weather Digest, vol. 27, no. 4, pp. 53-558, 2003.

[42] M. Matsueda, "Predictability of Euro-Russian blocking in summer of 2010," Geophysical Research Letters, vol. 38, no. 6, Article ID L06801, 6 pages, 2011.

[43] K. Birk, A. R. Lupo, P. Guinan, and C. E. Barbieri, "The interannual variability of midwestern temperatures and precipitation as related to the ENSO and PDO," Atmosfera, vol. 23, no. 2, pp. 95-128, 2010. 

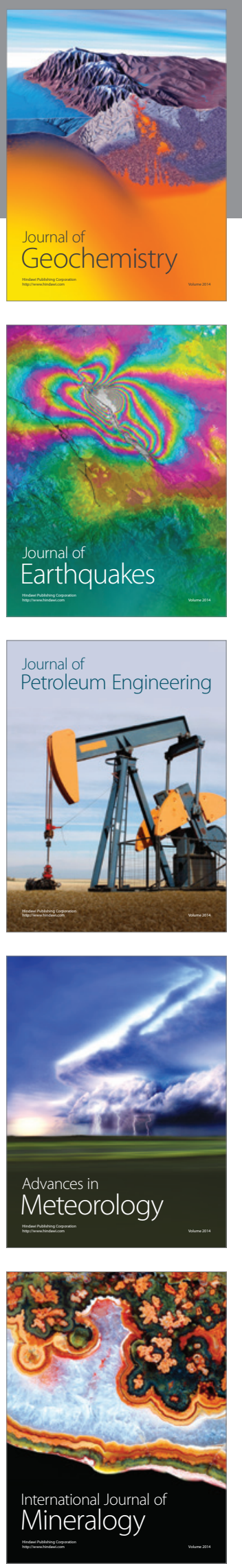
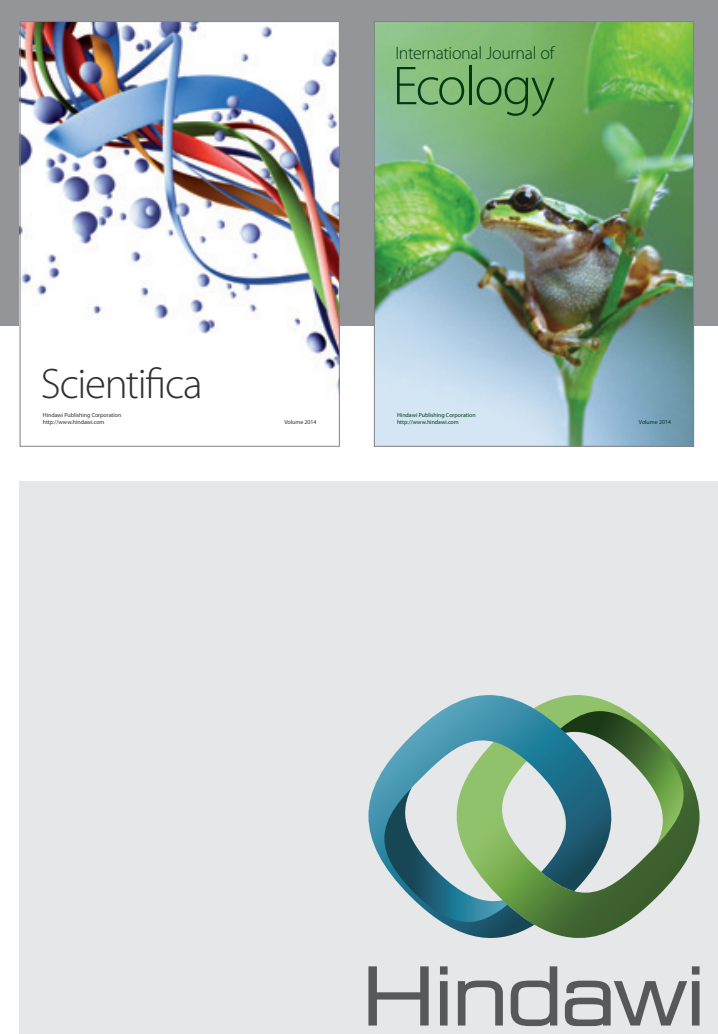

Submit your manuscripts at http://www.hindawi.com
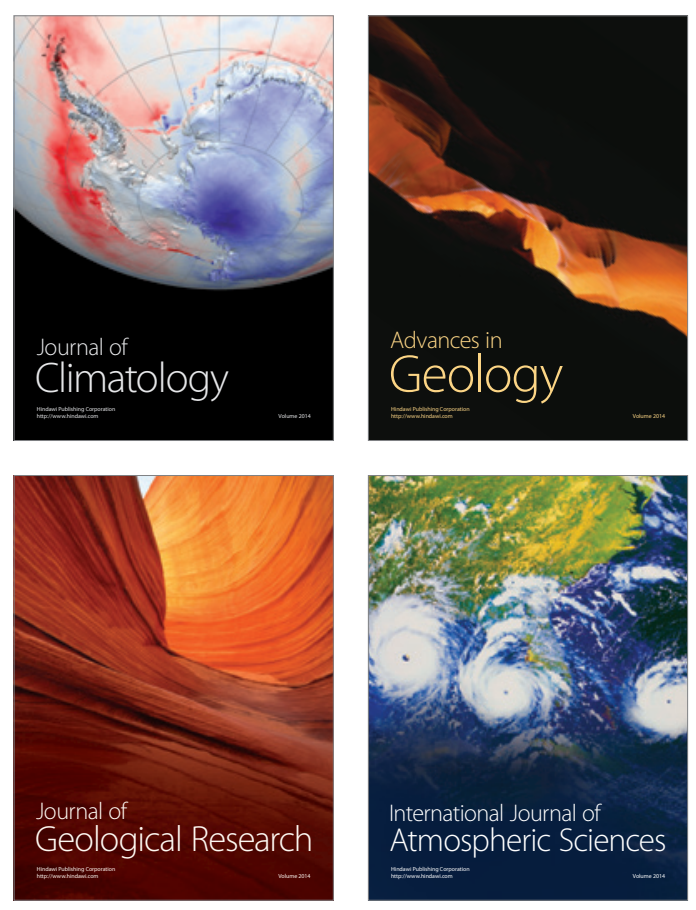
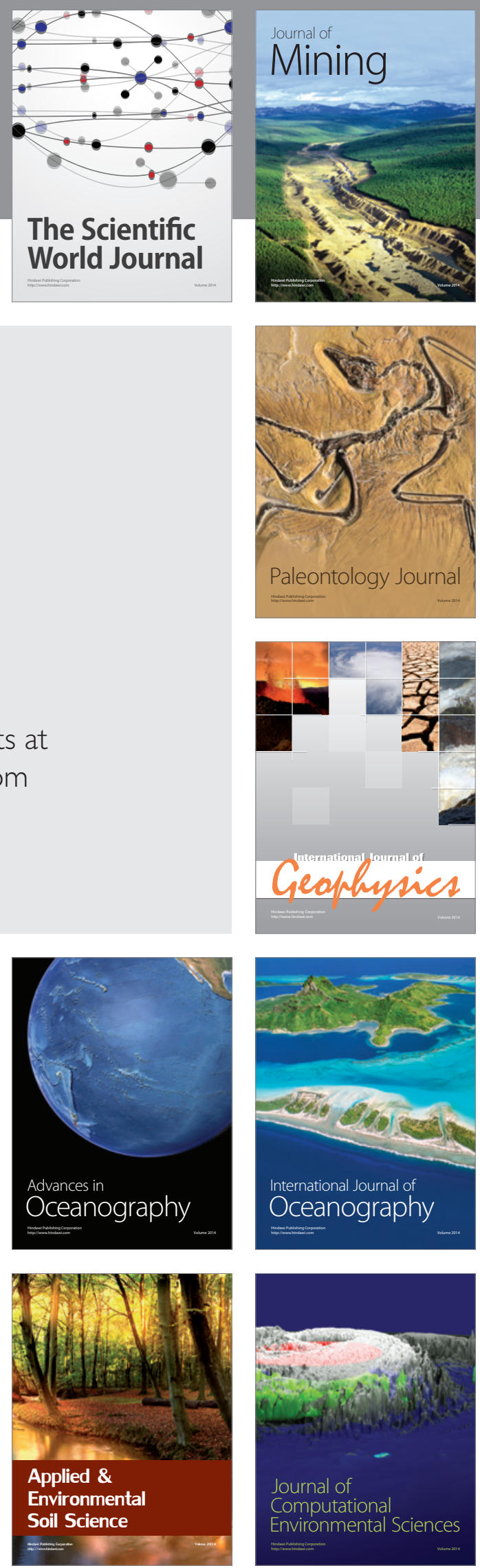